\title{
Comparing intra-oral wound healing after alveoloplasty using silk sutures and n-butyl-2-cyanoacrylate
}

\author{
Pratik Suthar, Sonal Shah, Pushkar Waknis, Gandhali Limaye, Aditi Saha, Pranav Sathe \\ Department of Oral and Maxillofacial Surgery, Dr. D. Y. Patil Vidyapeeth, Pune, India
}

\begin{abstract}
J Korean Assoc Oral Maxillofac Surg 2020;46:28-35)
Objectives: The need for proper wound closure is of paramount importance after any intra-oral surgery. Various wound closure techniques have been described in literature using traditional non-absorbable suture materials. These include like synthetic absorbable sutures, surgical staples and tissue adhesives. Cyanoacrylates are among the most commonly used biocompatible tissue adhesives. To evaluate and compare intraoral wound healing using 3-0 silk sutures and n-butyl-2-cyanoacrylate after alveoloplasty.

Materials and Methods: A total of 20 patients requiring bilateral alveoloplasty in the same arch (upper or lower) were included in this study. Patients with any pre-existing pathology or systemic disease were excluded. After alveoloplasty was performed, the wound was closed using 3-0 braided silk sutures on one side, and using n-butyl-2-cyanoacrylate bio adhesive on the other side. Patients were evaluated based on the following parameters: time required to achieve wound closure; the incidence of immediate and postoperative hemostasis; the time to the use of the first rescue medication; the side where pain first arises; and the side where wound healing begins first.

Results: Compared to 3-0 silk sutures, cyanoacrylate demonstrated better hemostatic properties, reduced operative time, reduced postoperative pain and better wound healing.

Conclusion: These data suggest that cyanoacrylate glue is an adequate alternative to conventional sutures to close the surgical wound after alveoloplasty, and better than are 3-0 silk sutures.
\end{abstract}

Key words: Alveoloplasty, Cyanoacrylate, N-butyl-2-cyanoacrylate, Tissue adhesive, Silk

[paper submitted 2018. 12. 17 / revised 1st 2019. 3. 27, 2nd 2019. 4. 19 / accepted 2019. 4. 24]

\section{Introduction}

The need for appropriate wound closure after any intraoral surgical procedure has always been a topic of concern. Dating back for thousands of years, there have been countless techniques used for closing surgical wounds. Regardless of the technique, the basic goals of surgical closure remain the same. These include reducing the dead space, minimizing risk of infection and properly approximating the wound edges to achieve an acceptable aesthetic and functional outcome.

\section{Sonal Shah}

Department of Oral and Maxillofacial Surgery, Dr. D. Y. Patil Vidyapeeth, Sant Tukaram Nagar, Pimpri, Pune 411018, India

TEL: +91-98-33459822 FAX: +91-20-27423427

E-mail:sonalbshah@rediffmail.com

ORCID: https://orcid.org/0000-0001-8424-0105

(C) This is an open-access article distributed under the terms of the Creative Commons Attribution Non-Commercial License (http://creativecommons.org/ licenses/by-nc/4.0/), which permits unrestricted non-commercial use, distribution, and reproduction in any medium, provided the original work is properly cited.

Copyright (C) 2020 The Korean Association of Oral and Maxillofacial Surgeons. All rights reserved.
Various wound closure techniques have been described in literature using traditional non-absorbable suture materials and advanced modalities, such as synthetic absorbable sutures, surgical staples and tissue adhesives.

Suturing has traditionally been the conventional method for approximating wound margins. However, suturing may cause permanent suture tracks, wound dehiscence, needle prick injuries, foreign body reactions, granulations, tissue ischemia, tissue tearing and infection ${ }^{1}$. Various alternative materials have been used for approximating wounds since ancient times, ranging from human hair to silk sutures. Although the modern suture materials and techniques are very sophisticated, the intended wound closure still may not be achieved ${ }^{2}$. Therefore, there is a need for alternative closure options.

This need led to an interest in tissue adhesives as substitutes for sutures to close surgical wounds. Previously ethyl and methyl cyanoacrylate were used for wound closure; however, they were discarded given their potential toxicities ${ }^{3}$. Newer generation cyanoacrylate includes n-butyl-2-cyanoacrylate, octyl-2-cyanoacrylate, and isoamyl 2-cyanoacrylate. 
N-butyl-2-cyanoacrylate has unique properties, including faster tissue bonding capacity and curing compared to those of octyl cyanoacrylate and iso-amyl 2-cyanoacrylate. In addition, its excellent tensile strength, fast polymerization, biocompatibility, immediate hemostasis, ease of application, and bacteriostatic properties make it a good choice to close surgical wounds. Given the superior properties that n-butyl2-cyanoacrylate has in comparison to those of other cyanoacrylates, it may also be better for wound healing. Therefore, we believe there is a need to clinically evaluate its role in intra-oral wound closure.

Setiya et al. ${ }^{4}$ evaluated the efficacy, advantages and disadvantages of cyanoacrylate glue for sutureless wound closure after surgical removal of impacted mandibular third molars. This study was performed on 50 patients with bilateral, symmetrically impacted third molars. Their analysis showed that there was significantly less postoperative pain, bleeding and swelling when cyanoacrylate was used for closure than there was with suturing. The use of cyanoacrylate also showed better hemostasis than did traditional suturing. However, healing was similar in both groups.

Alveoloplasty is a routine dental procedure that is associated with swelling, bleeding, and pain postoperatively. These types of surgical wounds are conventionally closed using resorbable or non-resorbable sutures and are allowed to heal by primary intention. However, suture can be challenging in this area due to inaccessibility. Suturing is time consuming, and requires adequate skill. At times, resorbable sutures must be removed early because they can be lodged with food and be irritating to the patient. Besides these difficulties, suturing also requires an additional visit for suture removal. In order to overcome these disadvantages, Besides these difficulties, suturing also requires an additional visit for suture removal. In order to overcome these disadvantages, the use of tissue adhesives (cyanoacrylate) in surgical procedures have been described in literature ${ }^{1,4-9}$.

In our study, we compare wound healing after alveoloplasty using silk and n-butyl-2-cyanoacrylate for surgical closure in 20 patients. We also compare the time to closure, hemostasis, and pain postoperatively. Finally, we compared wound healing between the two closure methods.

\section{Materials and Methods}

This prospective, randomized, an in vivo study was carried out from January 2016 to June 2017 in the Department of Oral and Maxillofacial Surgery at Dr. D. Y. Patil Dental
College \& Hospital, Pimpri, Pune, India. The study was approved by the Ethics Committee of Dr. D. Y. Patil Dental College \& Hospital (No. DYPDCH/760/2015/34). Twenty patients (4 females and 16 males) were included in this split mouth clinical study. Each patient underwent alveoloplasty under local anesthesia. Closure was achieved using either 3-0 black braided silk sutures or with n-butyl-2-cyanoacrylate bio adhesive (Endocryl; Samarth Life Sciences Pvt. Ltd., Mumbai, India). The parameter data were noted, tabulated and analyzed using the unpaired t-test and chi-square test.

Inclusion criteria were (1) patients with bilateral edentulous arches (both in the upper or lower arch) requiring alveoloplasty and (2) patients willing to participate in the study. Exclusion criteria included (1) patients with any pre-existing pathology and (2) patients with systemic diseases such as diabetes or anemia.

A detailed and thorough medical history was obtained from the patient, followed by meticulous physical examination. Valid written informed consent for the surgical procedure was obtained from each patient.

Investigations were included hemogram, bleeding time, clotting time, and blood sugar level.

Twenty patients who required alveoloplasty (and fulfilled the above mentioned criteria) were selected. All of the patients were informed about the procedure and the purpose, advantages and disadvantages of the study. The following preoperative laboratory tests were performed: hemogram, bleeding time, clotting time, and blood sugar level. Valid informed written consent was obtained from every patient. An equal volume of $2 \%$ lidocaine with 1:200,000 adrenaline was administered on each side. After administrating the local anesthetic agent, a coin toss method was used to select which side would be treated with cyanoacrylate and which with sutures. In the selected subjects, the surgical sites were divided into two treatment groups. Group 1 included wounds that would be closed with 3-0 braided silk sutures (Mersilk; Ethicon, Johnson \& Johnson Pvt. Ltd., Himachal Pradesh, India). Group 2 included wounds that would be closed using n-butyl-2-cyanoacrylate bio adhesive (Endocryl). A crestal incision with anterior release was made in all cases to expose the bony spicules. A triangular mucoperiosteal flap was raised. Bony projections were smoothened using a bone file or rongeur forcep. The wound was irrigated with saline.

Hemostasis was achieved. Hemostatic agents, such as collagen plugs or electrocautery, were not used during alveoloplasty. Wound closure was performed using either 3-0 silk or Endocryl. The following medications were given postopera- 


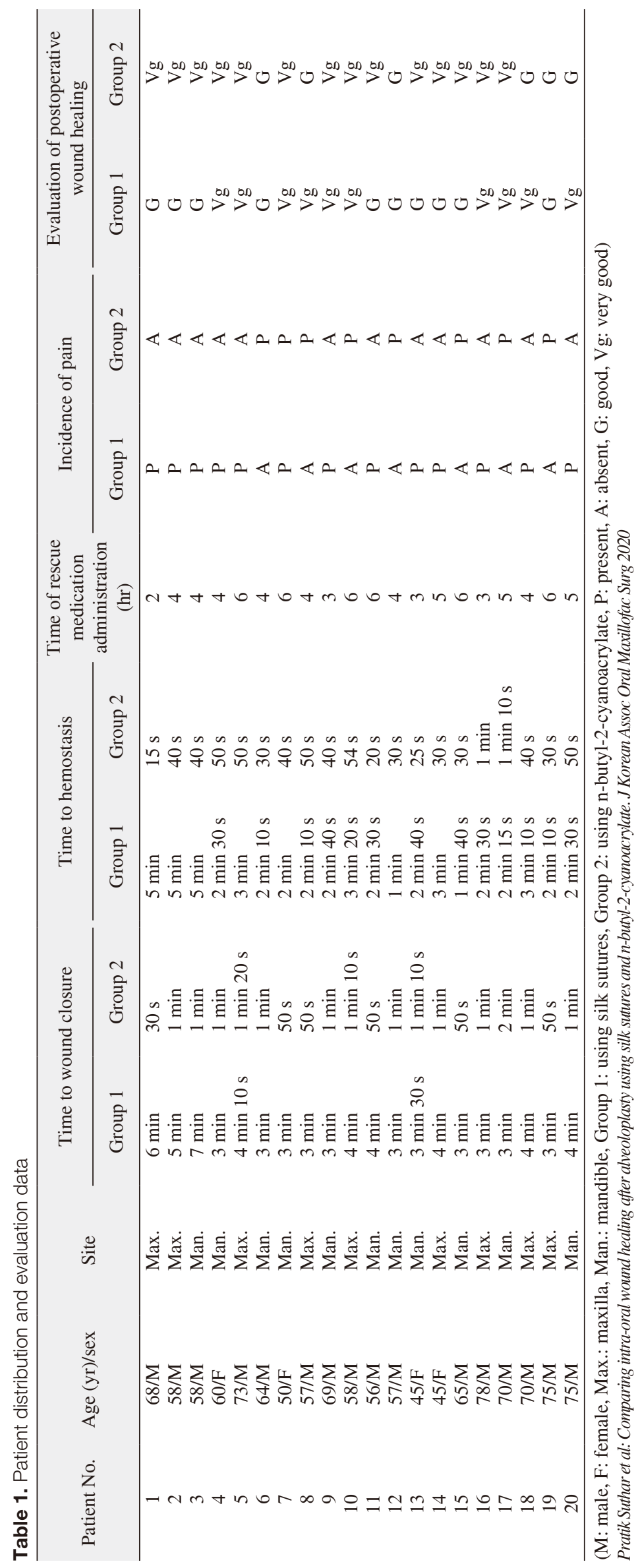


tively to all patients after wound closure:

- Cap. amoxicillin $500 \mathrm{mg}$ capsule three times daily for 5 days after the procedure.

- Tab. diclofenac sodium (50 mg, Voveran; Novartis India, Mumbai, India) twice daily for 5 days (rescue medication).

- Tab. ranitidine 150 mg (Rantac; JB Chemicals \& Pharmaceuticals, Pune, India) twice daily for 5 days to any patients with gastric irritation.

Postoperatively, patients were also given chlorhexidine mouthwash $0.12 \%$ (Perioguard; Colgate-Palmolive India, Mumbai, India) and instructed to rinse three times per day for 7 days.

The following postoperative parameters were used to evaluate the study subjects: (1) time to achieve wound closure, (2) incidence of immediate and postoperative hemostasis, (3) time to use of rescue medication was noted, (4) the side where pain first arises, (5) wound healing according to the Landry, Turnbull, and Howley index ${ }^{10}$, and (6) patient evaluation on the 1 st and 7 th postoperative days.

These values were recorded, tabulated and statistically evaluated.(Table 1)

\section{Results}

The data were compiled as shown in Table 1. The data were analyzed using the IBM SPSS Statistics (ver. 22.0; IBM, Armonk, NY, USA). A $P$-value less than 0.05 was considered statistically significant.

The mean time to wound closure in Group 1 was 3.77 \pm 1.11 minutes and $0.91 \pm 0.37$ minutes in Group 2 with a mean difference of 2.86 minutes ( $\mathrm{T}=10.917, P<0.001$ ).(Table 2, Fig. 1)

The mean time to achieve hemostasis in Group 1 was $2.71 \pm 1.11$ minutes and $0.44 \pm 0.23$ minutes in Group 2 with a mean difference of 2.26 minutes $(\mathrm{T}=8.873, P<0.001)$. (Table 3 , Fig. 2)

The percentage of patients without pain was $41.2 \%$ in Group 1 and 58.8\% in Group 2. The incidence of pain, in contrast, was $56.5 \%$ in Group 1 and $43.5 \%$ in Group 2 $\left(\chi^{2}=0.921, P=0.337\right)$. (Table 4, Fig. 3$)$

The mean rank value of postoperative wound healing was 18.50 in Group 1 and 22.50 in Group 2 (Mann-Whitney U value $=160.00, P=0.289$ ).(Table 5, Fig. 4)

\section{Discussion}

The principles of wound closure emphasize re-establishing functional soft tissue structural support, reducing wound tension and achieving everted skin edges. Precise approximation of wound margins and proper wound closure produces the most natural esthetic appearance and minimizes the need for later scar revision ${ }^{3}$.

A variety of materials have been used for wound closure, including metal clips (staples), adhesive tapes and sutures. Metal clips pose a greater risk for crosshatch marking and less precise wound approximation compared to those of other materials ${ }^{11}$. Adhesive tapes are used for wounds that are small, non-exudative and under minimal tension. These tapes can limit wound eversion and may have inconsistent adhesion. Sutures are the most commonly used wound closure materials. They are foreign materials that are woven through the skin and left in place for 5 to 10 days. Sutures that are

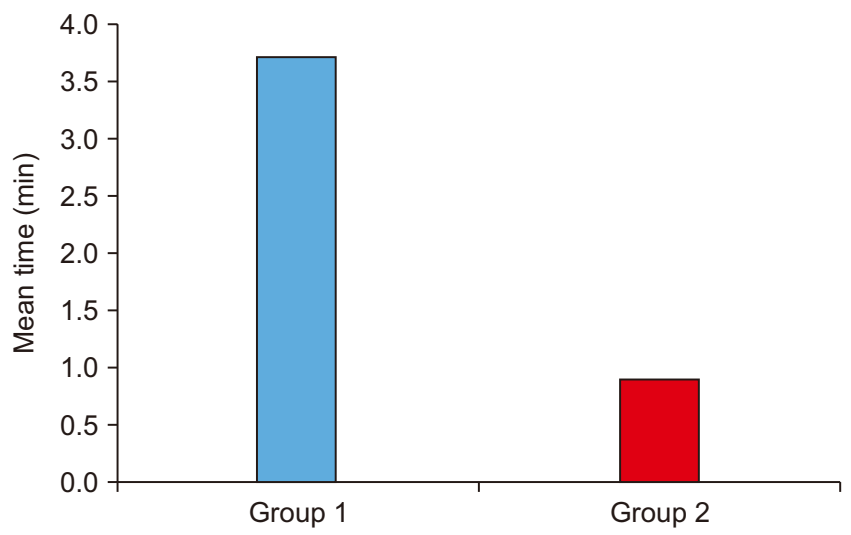

Fig. 1. Comparing the time to achieve wound closure. (Group 1: using silk sutures, Group 2: using n-butyl-2-cyanoacrylate) Pratik Suthar et al: Comparing intra-oral wound healing after alveoloplasty using silk sutures and n-butyl-2-cyanoacrylate. J Korean Assoc Oral Maxillofac Surg 2020

Table 2. Comparing the time to achieve wound closure

\begin{tabular}{lccccccc}
\hline & Group & No. of patients & Mean & SD & T & $P$-value & $\begin{array}{c}\text { Mean } \\
\text { difference }\end{array}$ \\
\hline Time to wound closure (min) & 1 & 20 & 3.770 & 1.1108 & 10.917 & $<0.001 *$ & 2.8600 \\
& 2 & 20 & 0.910 & 0.3726 & & \\
\hline
\end{tabular}

(Group 1: using silk sutures, Group 2: using n-butyl-2-cyanoacrylate, SD: standard deviation)

$* P<0.05$.

$P$-value by unpaired t-test.

Pratik Suthar et al: Comparing intra-oral wound healing after alveoloplasty using silk sutures and n-butyl-2-cyanoacrylate. J Korean Assoc Oral Maxillofac Surg 2020 
Table 3. Comparing the time to achieve hemostasis

\begin{tabular}{lcccccc}
\hline & Group & No. of patients & Mean & SD & T & $P$-value \\
& 1 & 20 & 2.7075 & 1.11760 & 8.873 & $<0.001^{*}$ \\
\hline $\begin{array}{c}\text { Time taken to achieverence } \\
\text { hemostasis (min) }\end{array}$ & 2 & 20 & 0.4420 & 0.23388 & & 2.26550 \\
\hline
\end{tabular}

(Group 1: using silk sutures, Group 2: using n-butyl-2-cyanoacrylate, SD: standard deviation)

$* P<0.05$.

$P$-value by unpaired t-test.

Pratik Suthar et al: Comparing intra-oral wound healing after alveoloplasty using silk sutures and n-butyl-2-cyanoacrylate. J Korean Assoc Oral Maxillofac Surg 2020

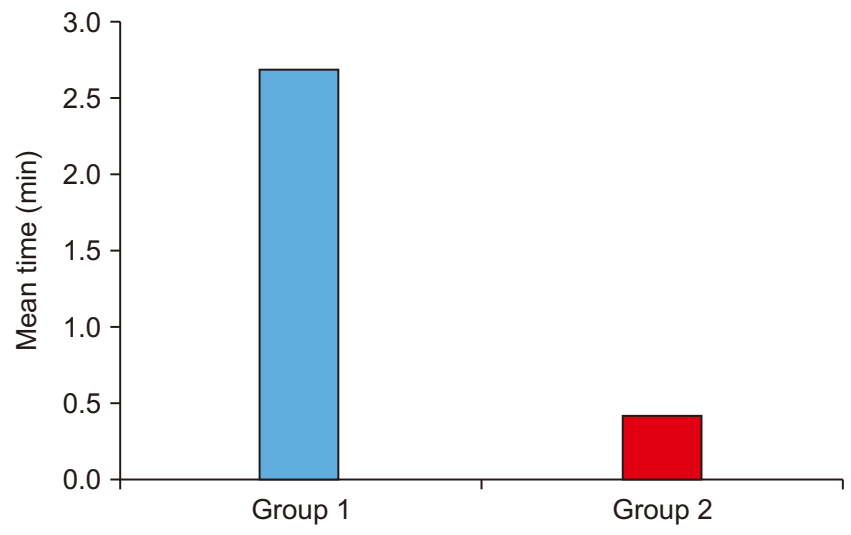

Fig. 2. Comparing the time to achieve hemostasis. (Group 1: using silk sutures, Group 2: using n-butyl-2-cyanoacrylate)

Pratik Suthar et al: Comparing intra-oral wound healing after alveoloplasty using silk sutures and n-butyl-2-cyanoacrylate. J Korean Assoc Oral Maxillofac Surg 2020

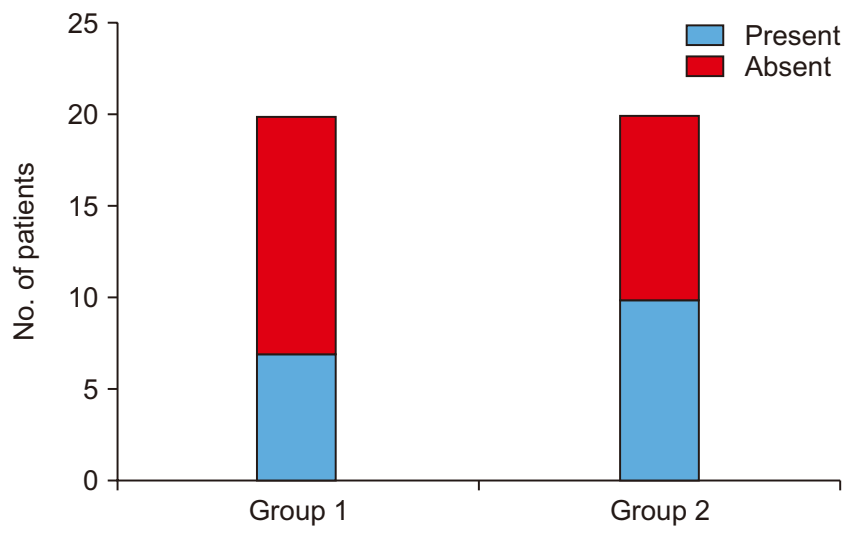

Fig. 3. Comparing postoperative pain between groups. (Group 1: using silk sutures, Group 2: using n-butyl-2-cyanoacrylate) Pratik Suthar et al: Comparing intra-oral wound healing after alveoloplasty using silk sutures and n-butyl-2-cyanoacrylate. J Korean Assoc Oral Maxillofac Surg 2020

Table 4. Comparing postoperative pain between groups

\begin{tabular}{|c|c|c|c|c|c|}
\hline & & \multicolumn{2}{|c|}{ Incidence of pain } & \multirow{2}{*}{$\chi^{2}$} & \multirow{2}{*}{$P$-value } \\
\hline & & Absent & Present & & \\
\hline \multirow[t]{3}{*}{ Group 1} & No. of patients & 7 & 13 & 0.921 & 0.337 \\
\hline & $\%$ within incidence of pain & 41.2 & 56.5 & & \\
\hline & $\%$ of total & 17.5 & 32.5 & & \\
\hline \multirow[t]{3}{*}{ Group 2} & No. of patients & 10 & 10 & & \\
\hline & $\%$ within incidence of pain & 58.8 & 43.5 & & \\
\hline & $\%$ of total & 25.0 & 25.0 & & \\
\hline \multirow[t]{3}{*}{ Total } & No. of patients & 17 & 23 & & \\
\hline & $\%$ within incidence of pain & 100.0 & 100.0 & & \\
\hline & $\%$ of total & 42.5 & 57.5 & & \\
\hline
\end{tabular}

(Group 1: using silk sutures, Group 2: using n-butyl-2-cyanoacrylate)

$P$-value by chi-square test.

Pratik Suthar et al: Comparing intra-oral wound healing after alveoloplasty using silk sutures and n-butyl-2-cyanoacrylate. J Korean Assoc Oral Maxillofac Surg 2020

tied too tight or left for too long can lead to the formation of suture tracks. Patients may also develop suture anxiety, which can lead to significant discomfort on their removal ${ }^{3}$.

In order to maximize adhesion and minimize patient discomfort, surgeons and physicians have proposed the use of tissue adhesives as a substitute for sutures in wound closure. Cyanoacrylates are one of the most commonly used tissue adhesives. Various Gelatin derivatives, such as Epoxide, Polyurethane and Resorcin, have been investigated for their use as tissue adhesives in surgery. Cyanoacrylates have gained wider acceptability and achieved a better outcome than have the gelatin derivatives. For the past 50 years, polymer adhesives have been used in medical and dental practice. One major drawback of polymers is that they are not tissue compatible, and may produce an extensive inflammatory reaction ${ }^{3}$.

By the early 1970s, cyanoacrylate glue was being used for mending bone, hide and tortoise shell. In the Vietnam War (1996) cyanoacrylate spray was used for hemostasis in wounded soldiers. Adhesives like n-butyl cyanoacrylate not only required less time for wound closure than did traditional methods, but also reduced the prevalence of infection and improved esthetics. The early short-chain tissue adhesives were 
Table 5. Comparing postoperative wound healing between groups

\begin{tabular}{clcccc}
\hline & Group & $\begin{array}{c}\text { No. of } \\
\text { patients }\end{array}$ & $\begin{array}{c}\text { Mean } \\
\text { rank }\end{array}$ & $\begin{array}{c}\text { Mann- } \\
\text { Whitney U }\end{array}$ & $P$-value \\
\hline Evaluation of & 1 & 20 & 18.50 & 160.00 & 0.289 \\
postoperative & 2 & 20 & 22.50 & & \\
wound healing & Total & 40 & & & \\
\hline
\end{tabular}

(Group 1: using silk sutures, Group 2: using n-butyl-2-cyanoacrylate) $P$-value by Mann-Whitney U-test.

Pratik Suthar et al: Comparing intra-oral wound healing after alveoloplasty using silk sutures and n-butyl-2-cyanoacrylate. J Korean Assoc Oral Maxillofac Surg 2020

effective but had limited use because they underwent rapid degradation into byproducts that had significant tissue toxicity. However, longer-chain cyanoacrylates degrade slowly, which limits the accumulation of toxic by-products in the tissues and makes them safe for topical skin closure. Therefore, in 1998, the U.S. Food and Drug Administration approved the use of the first topical skin adhesive. The following three cyanoarylate compounds are now used as topical skin adhesives: 2-octyl-cyanoacrylate (Dermabond and SurgiSeal), n-2-butylcyanoacrylate (Endocryl, Histocryl, Indermil, GluStitch, PeriAcryl, and LiquiBand) and 2-ethyl-cyanoacrylate (Epiglu).

Cyanoacrylate adhesives have a short shelf life and are moisture sensitive. The shelf life of cyanoacrylate can be extended from about one year to 15 months after manufacturing if they are kept unopened in a cool, dry area (such as a refrigerator at $55^{\circ} \mathrm{F}$ or $13^{\circ} \mathrm{C}$ ). If the adhesive is used within six months from the time of manufacturing, there is no need to refrigerate it. Similarly, open containers should not be refrigerated. Moving cyanoacrylate from a cool to a hot location can create condensation. In order to such condensation, the adhesive is allowed to reach room temperature before it is opened.

N-butyl 2-cyanoacrylates are biocompatible tissue adhesives that possess favorable properties, such as adequate flow and fast setting. They also have strong bonding properties and strength to hold tissue margins together. Valence bond and van der Waals force help in achieving tissue adhesion. After n-butyl-2-cyanoacrylate is applied, it forms a firm adhesive bond through exothermic polymerization with water, tissue moisture or blood. Cyanoacrylates are exothermic; therefore, heat is released by the polymerization reaction. They are also bacteriostatic. Wound sites that are closed with n-butyl2-cyanoacrylate have also shown reduced postoperative pain than those closed with other methods. Finally, cyanoacrylates are good hemostatic agents ${ }^{1}$.

However the exact mechanism by which n-butyl-2-cyanoacrylate achieves hemostasis is unclear. One hypothesis

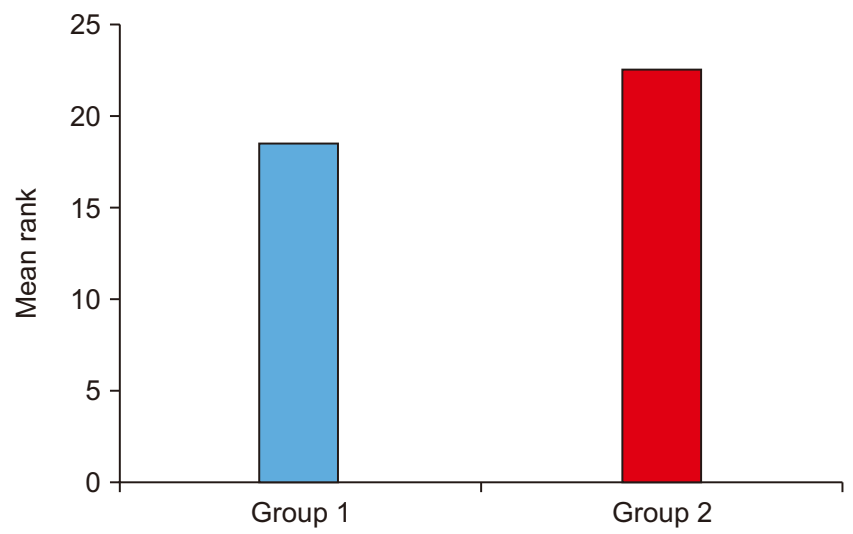

Fig. 4. Comparing postoperative wound healing. (Group 1: using silk sutures, Group 2: using n-butyl-2-cyanoacrylate)

Pratik Suthar et al: Comparing intra-oral wound healing after alveoloplasty using silk sutures and n-butyl-2-cyanoacrylate. J Korean Assoc Oral Maxillofac Surg 2020

states that the formation of a macrofilm by the ester causes mechanical blockage, which slows blood flow and provides a surface agent to activate the coagulation cascade. Evidence shows that the macrofilm forms a porous mass that is invaded by blood, and there is subsequent clotting within the pores of the adhesive ${ }^{3}$.

Cyanoacrylates offer various advantages, such as: effective and immediate hemostasis, ease of application, bacteriostatic properties, rapid adhesion to hard and soft tissues, maximum bonding strength and water resistant covering. They have a wide range of applications in surgery, as follows: repairing organs, vessels, skin and mucosal grafts; closing lacerations and incisions; dressing post-extraction wounds; and fixing mandibular fractures ${ }^{3}$.

In the field of maxillofacial surgery, wound closure using cyanoacrylates has been achieved in multiple settings, including extraction sockets, face, sinus perforations in sinus lift, biopsies, superficial oral ulcerations, gingivectomy, mucogingival flaps, and recurrent multiple aphthous ulcers ${ }^{4,6,12,13}$. Its use in general surgery is also prevalent in for wounds in the axilla, lungs ${ }^{4,6,13}$, heart and scalp ${ }^{6,11,14}$. It is also used as a hemostatic agent to control bleeding from skin grafts ${ }^{4,11,15,16}$, brow lifts, cosmetic surgeries ${ }^{4,6,17}$ and various anastomoses of intestines, arteries and nerves ${ }^{4,6,17}$.

In this study, 16 of the 20 patients were male and 4 were female ranging in age from 50 to 78 years (mean, 64 years). A single surgeon performed bilateral alveoloplasty in all of these patients, and performed the final closure using silk on one side and n-butyl-2-cyanoacrylate on the other. The time taken for closure using silk sutures ranged between 3 to 7 minutes. In contrast, the time for closure using n-butyl-2-cyanoacrylate ranged from only 30 to 2 minutes. Hemostasis 
using n-butyl-2-cyanoacrylate was achieved in $<1.5$ minutes, while it took up to 5 minutes to achieve hemostasis using silk sutures. The time to the use of rescue medications ranged from 2 to 6 hours. Six patients had pain on the side where nbutyl-2-cyanoacrylate was used, while 13 patients had pain on the side where silk sutures were placed. One patient presented with pain on both sides. This pain may be attributable to inadequate tissue coaptation between the wound edges, leading to inadvertent cyanoacrylate flow. This impaired flow might lead to collection of food debris, tissue irritation, inflammation and pain. Ten patients showed no significant differences in postoperative healing, while seven patients showed better wound healing with n-butyl-2-cyanoacrylate. Three patients showed better wound healing with silk sutures.

\section{Conclusion}

Cyanoacrylate glue can be used for wound closure after alveoloplasty. We found that glue has better hemostatic properties, reduces operative time and postoperative pain and swelling compared to those of silk suturing. The glue also enabled better wound healing than did suturing.

This procedure was also agreeable to the surgeon. Since the material is bacteriostatic, it offers protection against wound infection. The use of cyanoacrylate had several advantages, such as simplicity, higher speed and better hemostasis properties over those of suturing. It also does not require a second visit for suture removal. The cost of the adhesive was the only limitation to its use. Further prospective studies are needed to substantiate these results, and to assess the overall cost effectiveness of tissue adhesives compared to surgical sutures in low-tension elective procedures. Regardless, our findings suggest that cyanoacrylate glue is a better alternative to conventional suturing for wound closure after alveoloplasty.

\section{ORCID}

Pratik Suthar, https://orcid.org/0000-0002-9203-5803

Sonal Shah, https://orcid.org/0000-0001-8424-0105

Pushkar Waknis, https://orcid.org/0000-0002-8230-6075

Gandhali Limaye, https://orcid.org/0000-0002-7581-0935

Aditi Saha, https://orcid.org/0000-0002-2660-713X

Pranav Sathe, https://orcid.org/0000-0001-8265-8102

\section{Authors' Contributions}

P.S. participated in data collection and wrote the manu- script. S.S. and P.W. participated in the study design and performed the statistical analysis. G.L., A.S., and P.S. participated in the study design and coordination and helped to draft the manuscript. All authors read and approved the final manuscript.

\section{Ethics Approval and Consent to Participate}

The study was approved by the Ethics Committee of Dr. D. Y. Patil Dental College \& Hospital (No. DYPDCH/ $760 / 2015 / 34$ ), and the written informed consent was obtained from all patients.

\section{Conflict of Interest}

No potential conflict of interest relevant to this article was reported.

\section{References}

1. Kulkarni S, Dodwad V, Chava V. Healing of periodontal flaps when closed with silk sutures and N-butyl cyanoacrylate: a clinical and histological study. Indian J Dent Res 2007;18:72-7.

2. Kumar MS, Natta S, Shankar G, Reddy SH, Visalakshi D, Seshiah GV. Comparison between silk sutures and cyanoacrylate adhesive in human mucosa: a clinical and histological study. J Int Oral Health 2013;5:95-100.

3. Kumar VR, Rai AB, Priyayadav. Comparative evaluation of nbutyl cyanoacrylate and silk sutures in intra oral wound closure: a clinical study. J Adv Dent Res 2010;1:37-42.

4. Setiya S, Halli R, Shah A, Chhabaria G, Singh T. Comparative evaluation of efficacy of tissue glue and sutures after surgical removal of impacted mandibular third molars: a prospective controlled clinical study. J Oral Maxillofac Surg Med Pathol 2015;27:183-8.

5. Ghoreishian M, Gheisari R, Fayazi M. Tissue adhesive and suturing for closure of the surgical wound after removal of impacted mandibular third molars: a comparative study. Oral Surg Oral Med Oral Pathol Oral Radiol Endod 2009;108:e14-6.

6. Joshi AD, Saluja H, Mahindra U, Halli R. A comparative study: efficacy of tissue glue and sutures after impacted mandibular third molar removal. J Maxillofac Oral Surg 2011;10:310-5.

7. Waite PD, Cherala S. Surgical outcomes for suture-less surgery in 366 impacted third molar patients. J Oral Maxillofac Surg 2006;64:669-73.

8. Mizrahi B, Weldon C, Kohane DS. Tissue adhesives as active implants. Stud Mechanobiol Tissue Eng Biomater 2011;8:39-56.

9. Shivamurthy DM, Singh S, Reddy S. Comparison of octyl-2-cyanoacrylate and conventional sutures in facial skin closure. Natl J Maxillofac Surg 2010;1:15-9.

10. Landry RG, Turnbull RS, Howley T. Effectiveness of benzydamyne $\mathrm{HCl}$ in the treatment of periodontal post-surgical patients. Res Clin Forums 1988;10:105-18.

11. Eaton AC. A controlled trial to evaluate and compare a sutureless skin closure technique (Op-Site skin closure) with conventional skin suturing and clipping in abdominal surgery. Br J Surg 1980;67:857-60.

12. Singh A, Kohli M, Gupta N. Platelet rich fibrin: a novel approach 
for osseous regeneration. J Maxillofac Oral Surg 2012;11:430-4.

13. Petrovsky BV, Gigaury VS, Milonov OB, Perelman MI, Mlinchik VE, Gotye SV, et al. Surgical application of tissue adhesives. World J Surg 1980;4:331-6.

14. Bhaskar SN. Tissue response of rat tongue to normal and isobutyl cyanoacrylate. Oral Surg Oral Med Oral Pathol 1968;26:573-8.

15. Morton RJ, Gibson MF, Sloan JP. The use of histoacryl tissue adhesive for the primary closure of scalp wounds. Arch Emerg Med 1988;5:110-2.

16. Adler N, Nachumovsky S, Meshulam-Derazon S, Ad-El D. Skin graft fixation with cyanoacrylate tissue adhesive in burn patients. Burns 2007;33:803.

17. Kaplan M, Bozkurt S, Kut MS, Kullu S, Demirtas MM. Histopath- ological effects of ethyl 2-cyanoacrylate tissue adhesive following surgical application: an experimental study. Eur J Cardiothorac Surg 2004;25:167-72.

How to cite this article: Suthar $\mathrm{P}$, Shah $\mathrm{S}$, Waknis $\mathrm{P}$, Limaye G, Saha A, Sathe P. Comparing intra-oral wound healing after alveoloplasty using silk sutures and n-butyl-2-cyanoacrylate. J Korean Assoc Oral Maxillofac Surg 2020;46:28-35. https://doi. org/10.5125/jkaoms.2020.46.1.28 